\title{
Frequency of significant carotid artery disease on carotid angiography in patients with left main stem coronary artery disease.
}

\footnotetext{
1. MBBS

Postgraduate Resident Internal Medicine

Allied Hospital, Faisalabad.

2. MBBS, FCPS (Cardiology)

Assistant Professor Cardiology

Faisalabad Institute of Cardiology

Faisalabad

3. MBBS, FCPS (Cardiology)

Assistant Professor Cardiology

Faisalabad Institute of Cardiology

Faisalabad.
}

\section{Correspondence Address:}

Dr. Muhammad Yasir

Department of Cardiology

Faisalabad Institute of Cardiology

Faisalabad

yacir15@hotmail.com

Article received on:

21/05/2021

Accepted for publication:

10/07/2021

\begin{abstract}
Aatar Yaqoob ${ }^{1}$, Sonia William ${ }^{2}$, Muhammad Yasir $^{3}$
ABSTRACT... Objectives: To determine the frequency of significant carotid artery disease on carotid angiography in patients presenting with left main stem coronary artery disease. Study Design: Cross Sectional study. Setting: Department of Cardiology, Faisalabad Institute of Cardiology, Faisalabad. Period: October 2016 to April 2017. Material \& Methods: 140 patients were included in this study. To diagnose carotid artery disease, carotid angiography was performed. Imaging was performed while subjects were lying in a supine position. Arterial access gained through femoral artery and using Headhunter carotid angiography catheter (6F). Lateral, AP and ipsilateral oblique views was obtained. Results: Age ranges between 40-75 years with mean age of $53.91 \pm 7.05$ years. There were $94(67.2 \%)$ male patients while remaining 46 patients $(32.8 \%)$ were female. Carotid artery disease was found in 54 patients (38.6\%). Stratification with regard to gender and age was carried out. Conclusion: In conclusion, frequency of carotid artery disease in patients with left main stem coronary artery disease is high in our population. Therefore, screening of carotid artery disease should be recommended in patients with CAD, especially in older patients with multivessel CAD.
\end{abstract}

Key words: $\quad$ Atherosclerosis, Carotid Artery Disease, Left Main Stem Coronary Artery Disease.

Article Citation: Yaqoob A, William S, Yasir M. Frequency of significant carotid artery disease on carotid angiography in patients with left main stem coronary artery disease. Professional Med J 2021; 28(9):1252-1256. https://doi.org/10.29309/TPMJ/2021.28.09.6666

\section{INTRODUCTION}

Coronary artery disease (CAD) is the main cause of illness and death in industrialized countries and is also becoming the primary killer in poor countries worldwide. ${ }^{1}$ CAD results from genetic, dietary factors and sedentary life style. ${ }^{2}$ Left main coronary artery disease (LMCAD) is seen in about $6 \%$ of patients during coronary angiography. ${ }^{3}$

Incidence of carotid artery diseases is on the rise due to adoption of a sedentary lifestyle combined with excessive caloric intake. ${ }^{4}$ Studies revealed that old age, women; high blood pressure, previous stroke, Hemodialysis, peripheral arterial disease (PAD), and left main coronary artery disease are important risk factors for severe carotid artery stenosis. ${ }^{5}$

Coexistent carotid artery disease and multi vessel coronary artery disease (CAD) is not infrequent. One in 5 patients with multi vessel CAD has a severe carotid artery disease, and CAD incidence reaches $80 \%$ in those referred for carotid revascularization. Significant carotid disease is found in $16.6 \%$ of patients with triple vessel coronary artery disease. Carotid artery stenosis $>50 \%$ is seen in $5 \%$ of patients if they have single vessel CAD versus $40 \%$ if they have left main stenosis. ${ }^{6}$ In ischemic heart disease patients, coronary stenosis is found in $30-70 \%$ of patients. ${ }^{7}$ In one study, carotid stenosis was found in $37 \%$ patients of left main coronary artery stenosis. ${ }^{5}$

To the best of our knowledge, a few studies in this regard have been conducted in Pakistan. As there is controversy in literature, we want to conduct this study to know the exact burden of carotid stenosis in patients of significant left main coronary artery stenosis. With such awareness, health care providers should give more attention to prevent such complication caused by CAD involving left main. 


\section{Carotid Artery Disease}

Carotid artery disease was considered significant if there was carotid stenosis of $>50 \%$ on carotid angiography.

\section{Left Main Stem Coronary Artery Disease}

Left main was considered significant if there was left main stenosis of $>50 \%$ on coronary angiography.

\section{MATERIAL \& METHODS}

This Cross-sectional study was conducted at Angiography department, Faisalabad institute of cardiology, Faisalabad, in six months from 5-102016 to 04-04-2017.

The Sample Size was conducted By using WHO sample size calculator:

$\begin{array}{lll}\mathrm{P} & = & 37 \%(3) \\ \text { Confidence level } & = & 95 \% \\ \text { Absolute precision } & = & 8 \% \\ \text { Sample size } & = & 140\end{array}$

The Sampling Method was non-probability consecutive sampling.

\section{Inclusion Criteria}

Any gender between the ages of 40-75 years.

\section{Exclusion Criteria}

Patients who suffered heart attack, angioplasty or coronary bypass operation.

Renal Dysfunction I.e. serum creatinine of above $1.5 \mathrm{mg} / \mathrm{dl}$.

Hospital ethical committee approved study protocol (03-2015/MEC/FICS/FSD). Patients were recruited through OPD after taking consent. Demographic details were noted. For assessment of carotid artery disease, carotid angiography was performed using commercially available fluoroscopy machine (Siemens Artis Zee). Arterial assess gained through femoral artery and using Headhunter carotid angiography catheter (6F). Lateral, AP and ipsilateral oblique views were obtained. Quantification of carotid stenosis was performed by visual assessment. Data was collected on study proforma.
All the data was entered and analyzed on SPSS Version 17.0. Mean \pm Standard Deviation was calculated for age. Frequency and percentages were calculated for gender and carotid artery disease. Effect modifiers like age and gender were stratified and post-stratification chi-square test was applied. A P-value of below or equal to 0.05 was taken as significant.

\section{RESULTS}

140 patients took part in this study. Age ranges between $40-75$ years with mean age of $53.91 \pm 7.05$ years (Table-l). There were $94(67.2 \%)$ male patients while remaining 46 patients $(32.8 \%)$ were female (Table-II). Carotid stenosis was found in 54 subjects (38.6\%) (Table-III). Stratification with regard to gender and age was carried out and presented in Tables-IV and V.

\begin{tabular}{|l|c|}
\hline \multicolumn{1}{|c|}{ Age (Year) } & Number \\
\hline $40-50$ & $41(29.3 \%)$ \\
\hline $51-60$ & $82(58.6 \%)$ \\
\hline $61-75$ & $17(12.1 \%)$ \\
\hline Total & $140(100.0 \%)$ \\
\hline Mean \pm SD & $53.91 \pm 7.05$ \\
\hline
\end{tabular}

Table-I. Distribution of cases by age.

\begin{tabular}{|l|c|}
\hline \multicolumn{1}{|c|}{ Gender } & Number \\
\hline Male & $94(67.2)$ \\
\hline Female & $46(32.8)$ \\
\hline Total & $140(100.0)$ \\
\hline
\end{tabular}

Table-II. Distribution of cases by gender.

\begin{tabular}{|l|c|}
\hline \multicolumn{1}{|c|}{ Carotid Artery Disease } & Number \\
\hline Yes & $54(38.6)$ \\
\hline No & $86(61.4)$ \\
\hline Total & $140(100.0)$ \\
\hline
\end{tabular}

Table-III. Distribution of cases by carotid artery disease.

\begin{tabular}{|l|c|c|c|}
\hline \multirow{2}{*}{ Age (Year) } & \multicolumn{2}{|c|}{ Carotid Artery Disease } & \multirow{2}{*}{ Total } \\
\cline { 2 - 4 } & Yes & No & \\
\hline $40-50$ & 17 & 24 & 41 \\
\hline $51-60$ & 33 & 49 & 82 \\
\hline $61-75$ & 04 & 13 & 17 \\
\hline Total & 54 & 86 & 140 \\
\hline \multicolumn{3}{|c|}{ Table-IV. Stratification with regard to age. } \\
Chi-square value $=1.865$ \\
P-Value $=\mathbf{0 . 3 9 4}$
\end{tabular}




\begin{tabular}{|c|c|c|c|}
\hline \multirow{2}{*}{ Gender } & \multicolumn{2}{|c|}{ Carotid Artery Disease } & \multirow{2}{*}{ Total } \\
\hline & Yes & No & \\
\hline Male & 37 & 57 & 94 \\
\hline Female & 17 & 29 & 46 \\
\hline Total & 54 & 86 & 140 \\
\hline \multicolumn{4}{|c|}{$\begin{array}{l}\text { Table-V. Stratification with regard to gender. } \\
\text { Chi-square value }=0.075 \\
\text { P-Value }=0.784\end{array}$} \\
\hline
\end{tabular}

\section{DISCUSSION}

Globally most common causes of death are either heart attack or stroke. ${ }^{8}$ Their incidence increases with age and almost all the cases are due to underlying atherosclerosis. Atherosclerosis is a wide spread process and multiple vessels are usually involved when it becomes manifest. There is a strong association of carotid artery disease with triple vessel and left main stem coronary artery disease. ${ }^{9}$ This combination is important because of undesirable consequences of stroke during coronary artery bypass grafting in patients having significant carotid artery disease. ${ }^{10}$ Stroke further complicates the course of bypass patients. ${ }^{11}$

This study was conducted to know the exact burden of carotid stenosis in subjects with left main stem stenosis, and hence to sensitize the health care providers to treat left main stem disease with more holistic approach because majority of left main stem stenosis are still dealt with coronary artery bypass grafting.

Our study comprised of population of 140 consecutive patients of significant ( $\geq 50 \%$ stenosis) left main stem disease, the mean age of patients was $53.91 \pm 7.05 y$ years and there were $67.2 \%$ male and $32.8 \%$ female patients including diabetics as well as non-diabetics. All patients were enrolled through OPD, whether or not they were scheduled for CABG. Significant carotid disease ( $\geq 50 \%$ stenosis) was found in $38.6 \%$ of the patients.

The different modalities used for assessment of carotid artery disease were duplex scanning, carotid Doppler, computed tomographic angiography, cerebral angiography and magnetic resonance angiography. Currently, the patients with severe TVCAD and significant left main stem disease scheduled for CABG undergo screening for carotid artery disease by carotid duplex ultrasound with Doppler technique. Carotid angiography provides best detail of carotid stenosis especially in its bifurcation region so most surgeon demand it before surgery. There are however downsides of angiography e.g. its cost and invasive nature. Carotid Doppler is the most common screening tool. ${ }^{12}$

In a study by Qureshi et $\mathrm{al}^{13}$ it was found that Doppler ultrasound can identify symptomatic candidates with $80 \%$ accuracy but false positive rates were as high as $20 \%$. The PPV of carotid Doppler for identifying appropriate asymptomatic candidates for carotid intervention (angiographic stenosis $\geq 60 \%$ ) was $59 \%$ with false positive value of $41 \%$. Therefore, carotid disease needs to be confirmed by angiography before proceeding for any intervention.

Some conventional risk factors increase the prevalence of significant coronary artery disease and carotid atherosclerosis. A study by Sheiman $R G^{14}$, conducted on 295 patients showed that smoking, diabetes, hypertension, peripheral vascular diseases, left main stenosis were associated with significant carotid artery stenosis which was taken to be $\geq 50 \%$ stenosis on duplex scan. So it emphasized the need for carotid artery screening before coronary bypass grafting as the probability of detecting the carotid artery disease increase 2.98 times for each additional selection criteria. A study done at the Rawalpindi Institute of Cardiology by Kayani et al. ${ }^{15}$, included 140 patients with mean age of $59.6 \pm 7.1$ years. However, majority (56\%) of subjects had nonsignificant carotid stenosis and only $10.7 \%$ of patients had carotid stenosis of more than $50 \%$. In this study only $8.5 \%$ had carotid stenosis which qualify as critical (>70\%). However, in this study carotid stenosis was evaluated by carotid Doppler while in our study it was done on carotid angiography, which is gold standard. ${ }^{16}$

A study done by Adhikary et $\mathrm{al}^{17}$ in Bangladesh where 200 patients were evaluated. Again this study showed that $82.0 \%$ had mild carotid 
stenosis $<50 \%$ ). Approximately $18 \%$ of subjects had either moderate or severe carotid stenosis (severe being $>70 \%$ ). Another important finding was most of the patient $s$ were having unilateral disease

In a study at Punjab institute of cardiology by Shahid $^{18}$ et al employing carotid Doppler scan, it was found that diabetes increases the risk of severe diffuse disease in carotids as well as in coronaries among CABG patients. Total 379 patients undergoing elective CABG were assessed for carotid stenosis before operation and significant echo graphic carotid artery stenosis was taken as lesion with peak systolic velocity (PSV) of $>200$ at common carotid artery, bifurcation of carotid and internal carotid artery. Patients were divided into two groups, in first set of patients included $41.2 \%$ diabetic patients and second set included $58.8 \%$ non-diabetic patients. Left main coronary stenosis was seen in $37.8 \%$ of diabetes population and $20.2 \%$ without diabetes. Carotid artery stenosis was observed in 19.2\% diabetics as compared to $9 \%$ non-diabetics. Hence, it concluded that diabetes mellitus greatly augments the chances of left main stem coronary artery disease and carotid artery disease.

\section{CONCLUSION}

In conclusion, frequency of carotid artery disease in patients with left main stem coronary artery disease is high in our population. Therefore, screening of carotid artery disease should be recommended in patients with $\mathrm{CAD}$, especially in older patients with multivessel CAD to reduce the risk of complications.

\section{Copyright@ 10 July, 2021.}

\section{REFERENCES}

1. Nazeer M, Naveed T, Aman Ullah. A case control study of risk factors for coronary artery disease in Pakistani females. Ann King Edward Med Uni 2010; 16:62-8.

2. Beautner F, Teupser D, Gielen S, Holdt LM, Scholz M, Boudriot $E$, et al. Rationale and design of the leipzig (LIFE) heart study: Phenotyping and cardiovascular characteristics of patients with coronary artery disease. PLoS One 2011; 6: e29070.
3. Kawacki D, Morawiec B, Fudal M, Milejski W, Jachec W, Nowalany-Kozielska E. Comparison of coronary artery bypass grafting with percutaneous coronary intervention for unprotected left main coronary artery disease. Yonsei Med J 2012; 53: 58-67.

4. Hatori Y, Kitamura A, Nagatsuka K, Ihara M. A novel mouse model of ischemic carotid artery disease. PLoS One 2014; 9:e100257.

5. Wanamaker KM, Moraca RJ, Nitzberg D, Magovern GJ Jr. Contemporary incidence and risk factors for carotid artery disease in patients referred for coronary artery bypass surgery. J Cardiothorac Surg 2012; 7:78.

6. Dzierwa K, Pieniazek P, Musialek P, Piatek J, Tekieli $L$, Podolec $P$, et al. Treatment strategies in severe symptomatic carotid and coronary artery disease. Med Sci Monit 2011; 17:RA191-7.

7. Shahid M, Abid A, Dar MA, Noeman A, Amin S, Azhar $M$. Carotid disease in diabetic patients undergoing coronary artery bypass grafting. J Ayub Med Coll Abottabad 2011; 23:69-73.

8. Gupta S, Gudapati R, Gaurav K, Bhise M. Emerging risk disease in our population. Factors for cardiovascular diseases: Indian context. Carotid Indian J Endocrinol Metab 2013; 17:806-14.

9. Drohomirecka A, Kotowski L, Kwinecki P: Risk factors for carotid artery disease in patients scheduled for coronary artery bypass grafting. Kardiol Pol. 2010, 68: 789-794.

10. Naylor AR, Mehta Z, Rothwell PM: Carotid artery disease and stroke during coronary artery bypass: $A$ critical review of the literature. Eur J Endovasc Surg. 2002, 23:283-294.

11. Adeoye AM, Mullassari AS, Ramkumar SR, Latchumanadhas K. Cardiac Surgery. The risk of perioperative stroke in patients undergoing coronary bypass graft seen at Madras Medical Mission. Sahel Med J.3 2013; 16:43-7.

12. Gocke J, Hertzberg BS, Katanick S, Needleman L, Pellerito J, Polak JF, et al. Carotid artery stenosis: Gray scale and doppler us diagnosis-society of radiologists in ultrasound consensus conference. Radiology 2003; 229:340-6.

13. Qureshi I A, Fareed M Suri K, Ali Z, Stanley H. Kim: Role of conventional angiography in evaluation of patients with carotid artery stenosis demonstrated by doppler ultrasound in general practice. Stroke. 2001; 32:2287-2291. 
14. Robert G. Sheiman1 and Bertrand Janne d'Othée. Screening carotid Sonography before elective coronary artery bypass graft surgery: Who needs it. American Journal of Roentgenology. 2007; 188: W475-W479.

15. Kayani AM, Kamran $U$, Khan $N$, et al. Frequency of carotid artery disease in candidates undergoing coronary artery bypass graft. Pak Heart J 2015; 48: 24-27.
16. Saxena A Kwee $Y E$ Lim T S. Imaging modalities to diagnose carotid artery stenosis: Progress and prospect. Biomed Eng Online. 2019; 18: 66.

17. Adhikary D Ranjan R Mandal S et al. Prevalence of carotid artery stenosis in ischaemic heart disease patients in Bangladesh: Sage Open Medicine 2019 vol $7: 1-5$.

18. Shahid M, Abid R A. Dar A M. Carotid disease in diabetic patients undergoing coronary artery bypass grafting. Ayub Med Coll Abbottabad. Jul-Sep 2011; 23(3):69-73.

\begin{tabular}{|c|l|l|l|}
\hline \multicolumn{3}{|c|}{ AUTHORSHIP AND CONTRIBUTION DECLARATION } \\
\hline Sr. \# & Author(s) Full Name & Contribution to the paper & Author(s) Signature \\
\hline 1 & Aatar Yaqoob & Literature review. \\
\hline 2 & Sonia William & Data collection. & \\
\hline 3 & Muhammad Yasir & Paper writing. & 4 \\
\hline
\end{tabular}

